\title{
Population Subdivision of the Tri-Spine Horseshoe Crab, Tachypleus tridentatus, in Taiwan Strait
}

\author{
Ming-Che Yang', Chaolun Allen Chen ${ }^{1,3}$, Hwey-Lian Hsieh ${ }^{1}$ \\ and Chang-Po Chen ${ }^{1,2 *}$ \\ ${ }^{1}$ Research Center for Biodiversity, Academia Sinica, Nankang, Taipei 11529, Taiwan \\ ${ }^{2}$ Institute of Fishery Science, National Taiwan University, Taipei 10604, Taiwan \\ 3 Institute of Oceanography, National Taiwan University, Taipei 10604, Taiwan
}

\begin{abstract}
The genetic structure of the Asian tri-spine horseshoe crab, Tachypleus tridentatus, was investigated in three populations of Taiwan Strait using mitochondrial (mt) AT-rich region DNA sequences. We examined 23 individuals from Kinmen, an island located on the western side of Taiwan Strait, and 12 each from Tiexianwei and Dongwei near Magong Island in the Penghu Archipelago, in the middle of Taiwan Strait. DNA sequence analysis of 369 base pairs (bp) of the mt AT-rich region revealed 10 haplotypes among the 47 individuals, with a mean haplotypic diversity $(h)$ of $0.626 \pm 0.075$ and nucleotide diversity $(\pi)$ of $0.0039 \pm 0.00055$. Pairwise F-statistics $\left(F_{\text {ST }}\right)$ revealed significantly high gene flow between Kinmen and Dongwei $\left(F_{\mathrm{ST}}=-0.0351, p>0.05, N_{\mathrm{e}} m=\infty\right)$, but marked population subdivision and restricted gene flow between Kinmen and Tiexianwei $\left(F_{\mathrm{ST}}=0.1382\right.$, $\left.p<0.05, N_{\mathrm{e}} m=3.1176\right)$. Between populations at Magong Island, gene flow was moderate $\left(F_{\mathrm{ST}}=0.0634\right.$, $\left.p>0.05, N_{\mathrm{e}} m=7.3913\right)$. Mismatch distribution analysis indicated that the relatively low haplotype and nucleotide diversity observed in the Tiexianwei $T$. tridentatus population can be attributed to a recent bottleneck, probably due to isolation of Tiexianwei in semi-closed Magong Bay that prevents gene flow from neighboring populations.
\end{abstract}

Key words: tri-spine horseshoe crab, Tachypleus tridentatus, population genetics, mitochondrial AT-rich region, bottleneck, demographic history

\section{INTRODUCTION}

Marine organisms often show strong gene flow due to dispersal across wide geographic ranges (reviewed in Palumbi, 1994). Sampling species with high and intermediate dispersal abilities must be extensive, since gene flow often precludes genetic subdivision (Lessios et al., 1998). In contrast, the population structure can be distinct due to genetic drift, strong post-settlement selection (Hedgecock, 1986), and spatial-landscape patterns (Parsons, 1996; Johnson and Black, 1998; Watts and Johnson, 2004), as well as to a restricted dispersal capability (Collin, 2001). Species with a restricted dispersal capability are often composed of highly genetically structured populations with small geographic ranges, thus providing more opportunities to compare the depths and positions of intraspecific genetic divisions with the magnitude and locations of extrinsic factors (Bernardi and Talley, 2000).

Horseshoe crabs are ancient marine arthropods exhibiting life-history and habitat preferences that might indicate a restricted dispersal capability (reviewed in Sekiguchi, 1988). Limmulus polyphemus, the only Atlantic species, inhabits the eastern coast of North America from Maine to Mexico

\footnotetext{
* Corresponding author. Phone: +886-2-27899548; Fax : +886-2-27858059; E-mail: zocp@gate.sinica.edu.tw
}

doi:10.2108/zsj.24.219 (reviewed in Rutecki et al., 2004). Three Asian horseshoe crab species, including Tachypleus tridentatus, T. gigas, and Carcinoscorpius rotundicauda, are distributed sporadically from Southeast Asia to Japan (Sekiguchi, 1988; Morton, 1999). Mature horseshoe crabs migrate from the deeper continental shelf to low-energy, well-oxygenated sandy beaches near the high tide line for egg deposition and external fertilization during the breeding period. The hatched trilobite larvae of $L$. polyphemus swim freely for a short period and settle to the bottom in shallow waters of the intertidal zone near their natal beaches (Shuster, 1982). In contrast, $T$. tridentatus larvae tend to stay in their nests immediately after hatching, where they usually reside over winter, then leave the nests and reside at or near their natal beaches in the following spring or summer. Juveniles of $T$. tridentatus bury themselves in the sandy-mud bottom during high tide and feed during low tide (Sekiguchi, 1988; Chen et al., 2004; Chiu and Morton, 2004). Adults of $T$. tridentatus spend the winter on the offshore ocean bottom at depths of $20 \mathrm{~m}$ for hibernation, and then migrate from their winter deeper-water habitat to the shallow areas of coves when seawater temperatures rise (Sekiguchi, 1988). These life-history characteristics and habitat preferences suggest that the dispersal capability of horseshoe crabs might be restricted, resulting in substantial population subdivisions on a small geographic scale (Pierce et al., 2000).

Population genetic studies of horseshoe crabs have generally focused on Limulus polyphemus along the eastern 


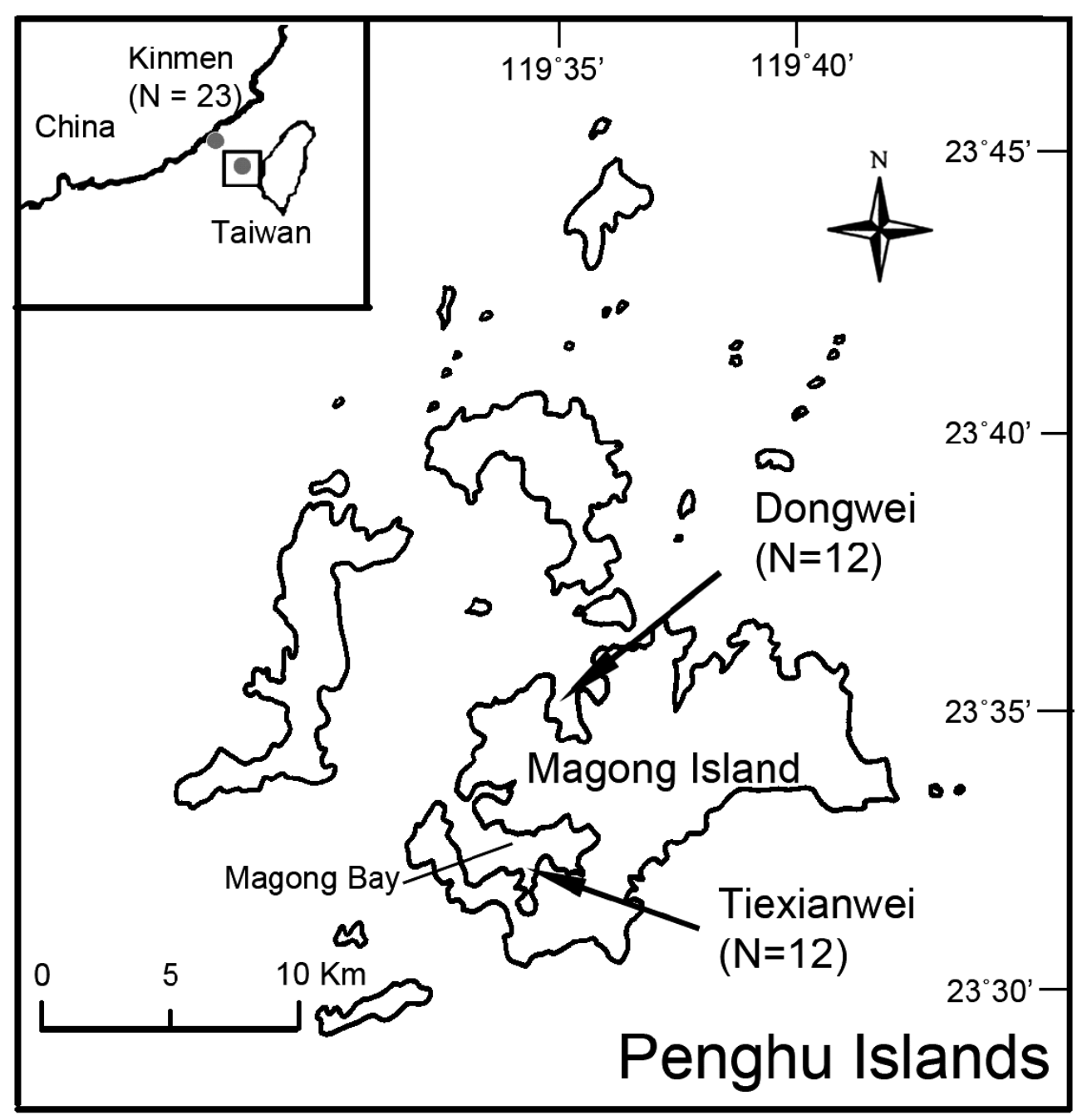

Fig. 1. Map of collection locations in Taiwan Strait. Horseshoe crabs, Tachypleus tridentatus were collected at 2 sites, Kinmen and the Penghu Islands, indicated by gray circles. Collections were made from two populations near Magong Island: Dongwei and Tixianwei that are indicated by arrows.

coast of North America (Saunders et al. 1986; Orti et al. 1997; Pierce et al., 2000; King et al., 2004). The existence of a genetic division between the Gulf of Mexico and Atlantic populations, a pattern observed for a variety of species (reviewed in Avise, 2004), has been detected using allozymes, restriction fragment length polymorphisms (RFLPs) of the mitochondrial ( $\mathrm{mt})$ genome, and microsatellites (Selander et al., 1970; Saunders et al., 1986; King et al., 2004). In contrast, limited gene flow on small scales was reported for sequence variants of the mtDNA cytochrome oxidase I (COI) 5'-end region in the Chesapeake Bay and Delaware Bay populations (Pierce et al., 2000).

The Asian tri-spine horseshoe crab, T. tridentatus, was formerly abundant in Southeast Asia to Japan (Sekiguchi, 1988). However, T. tridentatus in this region is declining, mainly due to loss of suitable spawning grounds because of coastal development and overharvesting for food and biomedical purposes (Itow, 1993; Chiu and Morton, 1999; Botton, 2001; Chen et al., 2004). Tachypleus tridentatus was once relatively abundant along the western coast of Taiwan and adjacent islands in Taiwan Strait. It is now thought that population of $T$. tridentatus is locally endangered along the western coast of Taiwan due to overfishing, land reclamation, and water pollution (Chen et al., 2004). Residual populations were only found in the Penghu Islands in the middle of Taiwan Strait, and around Kinmen Island off the Chinese mainland (Fig. 1). Conservation programs, including life-history investigations, public education, and translocation, have been promoted (Chen et al., 2004). Our study examines population structure and gene flow in the tri-pine horseshoe crab, $T$. tridentatus, from these two island groups in Taiwan Strait, in order to facilitate conservation efforts for this species. We analyzed genetic variation in the mt AT-rich region, which has proven to be a useful marker in intraspecific studies of some other arthropods (e.g., Drosophila subobscura, Brehm et al., 2001).

\section{MATERIALS AND METHODS}

Study sites and sample collection

Juveniles of $T$. tridentatus were surveyed and collected intertidally from sandy mudflats at both Kinmen Island and the Penghu Islands in 2002 and 2003 (Fig. 1). At Kinmen, juveniles were 
Table 1. Localities and molecular characters in the AT-rich region. Sample size (N), nucleotide content (AT $\%$ ), number of substitutions ( $\mathrm{Ti}$, transition; Tv, transversion), number of haplotypes $\left(\mathrm{N}_{h}\right)$, haplotypic diversity $(h)$, and nucleotide diversity $(\pi)$ ( \pm standard deviation; SD).

\begin{tabular}{lccccccr}
\hline Population & Code & $\mathbf{N}$ & $\mathbf{A}+\mathbf{T} \%$ & $\mathbf{T i}: \mathbf{T v}$ & $\mathbf{N}_{\boldsymbol{h}}$ & $\boldsymbol{h} \pm \mathbf{S D}$ & $\pi \pm$ SD \\
\hline Tiexianwei & $\mathbf{T}$ & 12 & 84.51 & $5: 0$ & 4 & $0.455 \pm 0.17$ & $0.00263 \pm 0.00216$ \\
Dongwei & $\mathbf{D}$ & 12 & 84.28 & $5: 0$ & 4 & $0.561 \pm 0.154$ & $0.00435 \pm 0.00295$ \\
Kinmen & $\mathbf{K}$ & 23 & 84.28 & $5: 0$ & 6 & $0.696 \pm 0.073$ & $0.00403 \pm 0.00282$ \\
\hline \multicolumn{1}{c}{ Total } & & 47 & 84.34 & $9: 0$ & 10 & $0.626 \pm 0.075$ & $0.0039 \pm 0.00055$ \\
\hline
\end{tabular}

obtained from Hsia Su $\left(20^{\circ} 58^{\prime} 58^{\prime \prime} \mathrm{N}, 118^{\circ} 35^{\prime} 49^{\prime \prime} \mathrm{E}\right)$. At Magong Island, the largest island in Penghu County, collecting was conducted with the guidance of local fishermen. Only two local populations, Dongwei $\left(23^{\circ} 35^{\prime} 00^{\prime \prime} \mathrm{N}, 1^{\circ} 9^{\circ} 35^{\prime} 40^{\prime \prime} \mathrm{E}\right)$ and Tiexianwe

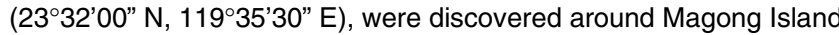
after intensive field surveys. Dongwei is an open bay facing the Inner Sea, whereas Tiexianwei is located in Magong Bay, a semiclosed bay (Fig. 1). All individuals were preserved in $95 \%$ ethanol immediately after collection. In total, $47 \mathrm{~T}$. tridentatus juveniles were used in this study.

\section{Genomic DNA extraction, PCR, and DNA sequencing}

Total genomic DNA was extracted from muscle tissues using the Blood \& Tissue Genomic DNA Extraction Miniprep System Kit (VIOGENE, Taipei) following the instructions provided by the supplier. The complete mt AT-rich region was amplified by a pair of primers, Hb-trna (5'-GAGCCCAATAGCTTAAAT TAGCTTA-3') and Hb-12S (5'-GTCTAACCGCGGTAGCTGGCAC-3'), designed from the published $\mathrm{mt}$ genome of $L$. polyphemus (Lavrov et al., 2000). Amplification reactions were conducted in $50-\mu \mathrm{L}$ volumes using the buffer supplied with the enzyme and under the conditions recommended by the manufacturer. Each $50-\mu \mathrm{L}$ volume contained $50 \mathrm{mM} \mathrm{KCl}, 10$ $\mathrm{mM}$ Tris ( $\mathrm{pH}$ 9.0), $3 \mathrm{mM} \mathrm{MgCl}_{2}, 0.2 \mathrm{mM}$ each dNTP, $0.04 \mathrm{mM}$ each primer, 0.033 units of Taq polymerase (Invitrogen, Karlsruhe, Germany), $1 \mu \mathrm{L}$ DMSO, and $50 \mathrm{ng}$ of genomic DNA. PCR was performed in a PC-9606 thermal sequencer (Corbett Research, Mortlake, Australia) using the following thermal cycle: 1 cycle at $95^{\circ} \mathrm{C}(3 \mathrm{~min}) ; 30$ cycles at $94^{\circ} \mathrm{C}(30 \mathrm{~s}), 50^{\circ} \mathrm{C}(1 \mathrm{~min})$, and $72^{\circ} \mathrm{C}(2$ $\mathrm{min})$, and one cycle at $72^{\circ} \mathrm{C}(2 \mathrm{~min}), 25^{\circ} \mathrm{C}(5 \mathrm{~min})$. The PCR products were electrophoresed on a $1 \%$ agarose (FMC Bioproduct, Rockland, ME USA) gel in 1X TAE buffer to check the yield. The amplified DNA was extracted using a DNA/RNA gel extraction column (Viogene, Taipei) under conditions recommended by the manufacturer. The nucleotide sequences were determined from both ends by direct sequencing of the PCR products with an ABI 377 Genetic Analyzer. Sequences obtained in this study have been submitted to GenBank under accession numbers DQ516529 DQ516538.

\section{Sequence and population-genetic analyses}

DNA sequences were initially assembled and aligned using the program SeqMan ${ }^{\text {TM }}$ II (DNASTAR, Madison, WI), followed by manual editing using SeqApp 1.9 (Gilbert, 1994). All data analyses were implemented using Arlequin 2.0 for a Macintosh platform (Schneider et al., 2000). Unique haplotypes and all transitions and transversions were counted. Haplotype diversity $(h)$, nucleotide diversity $(\pi)$ (Nei, 1987), and their standard errors were calculated. Pairwise Fstatistics $\left(F_{\mathrm{ST}}\right)$ were calculated as genetic distances based on pairwise differences (Gamma $\alpha$ value $=0.248$ ) between populations (Reynolds et al., 1983; Slatkin, 1995). The null distribution of pairwise $F_{\mathrm{ST}}$ values under the hypothesis of no difference between populations was obtained by permuting haplotypes between populations in 1,000 permutation simulations. An indirect estimate of gene flow was calculated based on the equation, $N_{\mathrm{e}} m=1 / 2\left[\left(1 / F_{\mathrm{ST}}\right)-1\right]$, where $N_{\mathrm{e}}$ is the effective number of females and $m$ is the migration rate. The historical demography of $T$. tridentatus was examined using mismatch distribution analysis (MDA) based on the observed number of differences among all pairs of haplotypes (Rogers and Harpending, 1992). Simulation studies have shown that the distribution is multimodal in samples drawn from populations at demographic equilibrium, a pattern reflecting stochastic lineage loss; a unimodal distribution suggests stationary population growth, and a Poisson distribution indicates a recent bottleneck effect. However, one concern about using MDA for a group of subdivided populations is that the assumption of random mating is violated (Hoffman and Blouin, 2004). Rogers and Harpending (1992) showed that the theory behind MDA is robust and should approximately hold true even when populations are completely isolated. Moreover, when subdivided populations are linked by gene flow, an even better fit to the random mating approximation should be obtained (Hoffman and Blouin, 2004).

\section{RESULTS}

\section{Mitochondrial AT-rich region sequence variation}

Using primers designed from the homologous regions in the $12 \mathrm{~S}$ rRNA and tRNA-Met genes of the American horseshoe crab, L. polyphemus (Lavrov et al., 2000), we determined the complete nucleotide sequence of the $T$. tridentatus mtAT-rich region, two tRNA genes, and a partial sequence of the flanking region of $12 S$ rRNA. The length of the PCR fragment was 689 base pairs (bp), including 183 bp of $12 S$ rRNA, $67 \mathrm{bp}$ for tRNA-lle, and $67 \mathrm{bp}$ for tRNA-GIn. The total length of the AT-rich region was $369 \mathrm{bp}$ in T. tridentatus. In total, 10 haplotypes of the AT-rich region with nine variable sites were identified from $47 \mathrm{~T}$. tridentatus individuals in three populations (Table 1). Overall and population-specific nucle-

Table 2. Variable sites found in a fragment of the AT-rich region of Tachypleus tridentatus and their distribution in the populations. Nine variable sites were found in a fragment of the AT-rich region in 47 horseshoe crabs defining 10 haplotypes $(\mathrm{H} 01-\mathrm{H} 10) . \mathrm{K}, \mathrm{T}$, and $\mathrm{D}$ represent the populations in Kinmen, Tixianwei, and Dongwei, respectively. H01 was the most-common haplotype.

\begin{tabular}{|c|c|c|c|c|c|c|c|c|c|c|c|c|c|}
\hline & \multicolumn{9}{|c|}{ Nucleotide positions } & \multicolumn{4}{|c|}{ Populations } \\
\hline & & & 1 & 1 & 1 & 2 & 2 & 2 & 2 & & & & \\
\hline & 3 & 7 & 2 & 3 & 5 & 2 & 4 & 9 & 9 & & & & \\
\hline & 5 & 8 & 4 & 1 & 1 & 1 & 2 & 2 & 8 & $\mathrm{~K}$ & $\mathrm{~T}$ & D & Total \\
\hline $\mathrm{H} 01$ & $\mathrm{~T}$ & A & $G$ & $T$ & C & A & $T$ & A & A & 11 & 9 & 8 & 28 \\
\hline $\mathrm{H} 02$ & $\bullet$ & $\bullet$ & $A$ & - & - & $\bullet$ & • & • & • & 1 & & & 1 \\
\hline $\mathrm{H} 03$ & • & $G$ & - & - & - & $\mathrm{G}$ & C & - & $\bullet$ & & & 1 & 1 \\
\hline $\mathrm{HO} 4$ & $\mathrm{C}$ & $\bullet$ & - & C & - & $G$ & $\bullet$ & • & • & 2 & & & 2 \\
\hline H05 & $\bullet$ & $G$ & - & • & - & $G$ & • & $G$ & • & & 1 & 1 & 2 \\
\hline H06 & $\bullet$ & • & - & • & $\mathrm{T}$ & • & • & • & $\bullet$ & & 1 & & 1 \\
\hline $\mathrm{H} 07$ & • & • & • & • & $\mathrm{T}$ & • & • & • & $G$ & & 1 & & 1 \\
\hline H08 & • & $\mathrm{G}$ & $\bullet$ & • & • & $\mathrm{G}$ & • & • & • & 7 & & & 7 \\
\hline Ho9 & C & $\mathrm{G}$ & • & • & • & $\mathrm{G}$ & • & • & • & 1 & & 2 & 3 \\
\hline $\mathrm{H} 10$ & • & • & • & • & • & $\mathrm{G}$ & • & • & • & 1 & & & 1 \\
\hline
\end{tabular}


otide composition, number of haplotypes, haplotype diversity, and nucleotide diversity are presented in Table 1. A common haplotype, H01, was shared by 28 individuals (60\%) among the three populations in Taiwan Strait (Table 2).

\section{Population structure, gene flow, and mismatch-distribu- tion analyses}

For tri-spine horseshoe crabs, geographic distance between the populations of different localities was not reflected in the degree of genetic differentiation between them

Table 3. Pairwise F-statistic $\left(F_{\mathrm{ST}}\right)$ values of genetic differentiation and female migrants per generation $\left(N_{\mathrm{e}} m\right)$ values of gene flow among horseshoe crab populations. $F_{\mathrm{ST}}$ values are above the diagonal, and $N_{\mathrm{e}} m$ values are below the diagonal.

\begin{tabular}{cccc}
\hline Population & Tiexianwei & Dongwei & Kinmen \\
\hline Tiexianwei & - & $0.0634^{\mathrm{ns}}$ & $0.1382^{\star}$ \\
Dongwei & 7.3913 & - & $-0.0345^{\text {ns }}$ \\
Kinmen & 3.1176 & Infinite & - \\
\hline
\end{tabular}

${ }^{*} p<0.05 ; \quad{ }^{n s}$ not significant
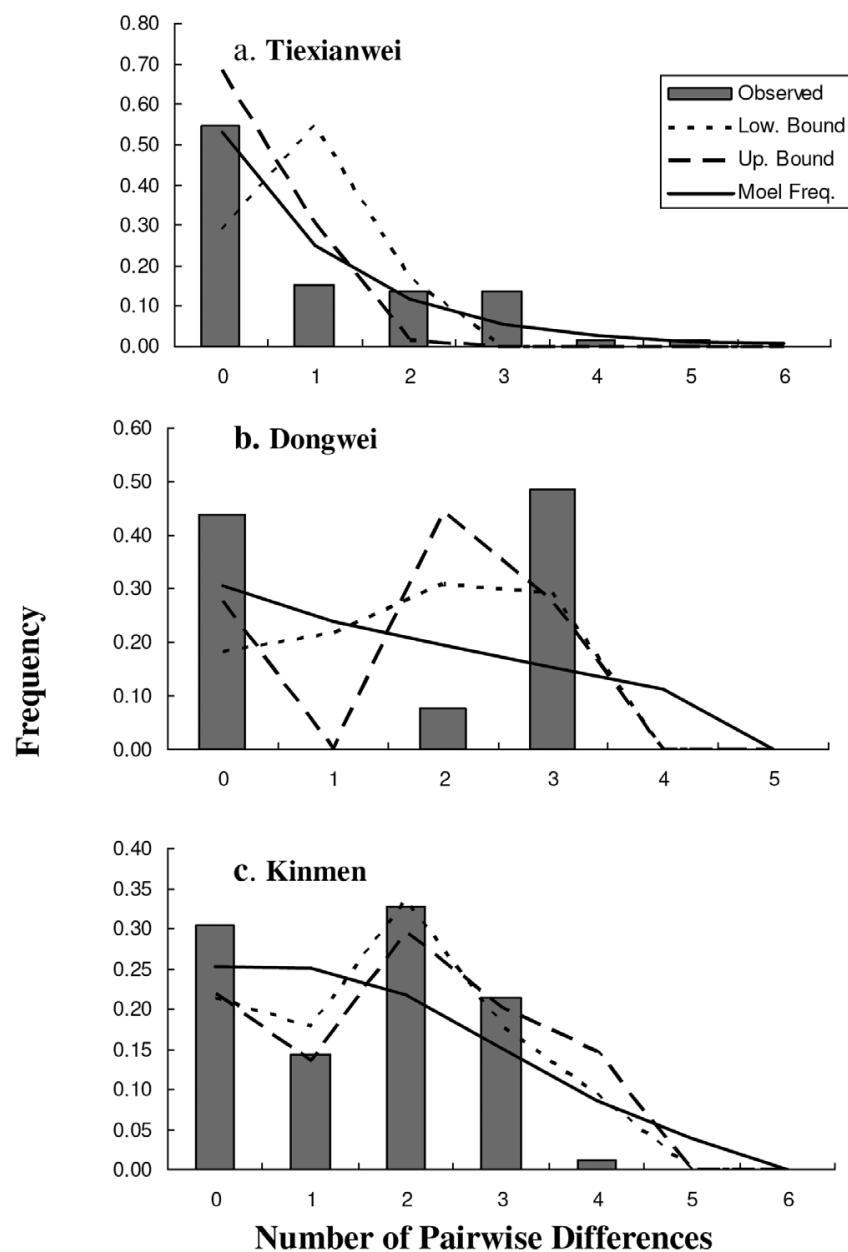

Fig. 2. Mismatch distribution analyses of the Tachypleus tridentatus AT-rich region pairwise sequence differences as computed by ARLEQUIN 2.0. The observed distributions (bars) are compared to the sudden expansion model illustrated by the overlaid curve (solid line), and dashed lines are the 5 (low boundary) and 95(up boundary) percentile values of 1000 simulated samples.
(Table 3). Population pairwise $F_{\mathrm{ST}}$ values were low both between Dongwei and Tiexianwei $\left(F_{\mathrm{ST}}=0.0634, p>0.05\right)$ at Magong Island, and between Dongwei and Kinmen ( $F_{\mathrm{ST}}=$ $-0.0351, p>0.05$ ), indicative of a high degree of gene flow between these pairs of populations; however these values were not statistically significant. A negative $F_{S T}$ value indicates great differences between two random individuals from the same population, rather than between two random individuals from different populations (Arnason and Palsson, 1996). In contrast, the $F_{S T}$ value between Tiexianwei and Kinmen was 0.1382 , indicative of restricted gene flow, and this value was statistically significant $(p<0.05)$. The number of female migrants per generation $\left(N_{\mathrm{e}} m\right)$ indirectly estimated from the inverted $F_{\mathrm{ST}}$ values was infinite between Dongwei and Kinmen, moderate between Dongwei and Tiexianwei $\left(N_{\mathrm{e}} m=7.3913\right)$, and relatively low between Tiexianwei and Kinmen $\left(N_{\mathrm{e}} m=3.1176\right)$. Mismatch distribution analyses and simulations suggested that the tri-spine horseshoe crabs at Dongwei and Kinmen yield a ragged distribution of pairwise differences (Fig. 2b, c), as might be expected from a stable population at equilibrium (Rogers and Harpending, 1992). In contrast, the Tiexianwei population exhibited an approximate Poisson distribution of pairwise differences, suggesting a recent population bottleneck (Fig. 2a).

\section{DISCUSSION}

Population genetic analysis of the mitochondrial (mt) AT-rich region demonstrated that the Asian tri-spine horseshoe crab, Tachypleus tridentatus, displays genetic subdivision over a relatively small geographic range. Genetic subdivision is anticipated for marine species for which adults are relatively immobile and larvae are non-dispersive, although genetic isolation has also been found in species with a high level of adult migration or with long-lived planktonic larvae (reviewed in Avise, 2004). Adults of T. tridentantus stay on the offshore ocean bottom and migrate to shallow areas for reproduction (Sekiguchi, 1988). Trilobite larvae settle right after hatching, and juveniles spend their life stages at or near the natal beach for feeding (Sekiguchi, 1988; Chen et al., 2004). These life-history traits indicate that the tri-spine horseshoe crab has limited adult migratory abilities and limited dispersal of larvae; as a consequence, it should exhibit genetic subdivision between populations and isolation-by-distance. However, our observations do not fulfill these predictions. Despite small sample sizes, two populations at Magong Island, Dongwei and Tiexianwei, separated by $15 \mathrm{~km}$, showed moderate gene flow. However, strikingly different results were observed at the larger geographic distance $(>150 \mathrm{~km})$. The tri-spine horseshoe crabs of Kinmen and Dongwei showed a negative $F_{\mathrm{ST}}$ value, indicating there to be unrestricted gene flow. In contrast, the $F_{\mathrm{ST}}$ value $(p<0.05)$ between Kinmen and Tiexianwei is indicative of restricted gene flow. These contrasting results highlight that life history characteristics alone cannot entirely explain the genetic structure of tri-spine horseshoe crab populations in Taiwan Strait.

The discovery of substantial population subdivision in $T$. tridentatus between Kinmen and Tiexianwei in Taiwan Strait is not surprising. A similar pattern was also observed in a comparison of two populations of American horseshoe crab, L. polyphemus, along the east coast of North America using 
mt COI DNA sequences (Pierce et al., 2000). For $L$. polyphemus, it has long been known that there is a genetic "break" between the Gulf of Mexico and Atlantic populations (Saunder et al., 1986; Orti et al., 1997; King et al., 2004), a pattern also seen for a variety of other coastal and marine species (reviewed in Avise 2001, 2004). In contrast, mtDNA variation in the upper Chesapeake Bay and Delaware Bay demonstrate that gene flow between populations inhabiting the sampled sites is restricted (Pierce et al., 2000). This suggests that the American horseshoe crabs in the upper Chesapeake Bay population are resident, separate from the larger shelf-inhabiting population found in Delaware Bay (Pierce et al., 2000). A similar explanation might apply to $T$. tridentatus of Tiexianwei. Magong Bay is semi-closed, and as a consequence the population there might have limited genetic exchange with populations outside the bay.

Differences in demographic history also shade the patterns of mtDNA sequence variation and genetic subdivision among the three $T$. tridentatus populations. Low haplotype diversity, low nucleotide diversity, and an approximately Poisson mismatch distribution imply the genetic consequences of a population bottleneck (Nei et al., 1975; reviewed in Avise, 2001, 2004). This pattern was observed only for the tri-spine horseshoe crab population at Tiexianwei. For the Dongwei and Kinmen populations, there was an indication of stable populations at equilibrium. The population bottleneck could have resulted from genetic drift in a small population, as if it were neutrally rising to fixation with about the same probability as strictly neutral change (Kimura, 1979); genetic drift with sufficient time is also one of the causes of diversification among populations (Frankham et al., 2002; Avise, 2004). A similar demographic difference was also observed in $L$. polyphemus in Delaware and Chesapeake Bays of the East Coast of the US. The population in the former was suggested as being a bottleneck population, whereas the latter was suggested to be a stable population at equilibrium (Pierce et al., 2000). The recent population bottleneck in Delaware Bay can be attributed to population reduction by overharvesting for commercial bait early in the last century (Pierce et al., 2000). Despite the geographical isolation, loss of habitat for natal grounds in Magong Harbor might also be causing loss of genetic diversity in the Tiexianwei population of $T$. tridentatus. Development of Magong Harbor began over two centuries ago, and modification of habitat by construction with cement continued into the early 20th century. The consequent loss of sandy beaches for spawning and feeding grounds might have strengthened the isolation of the Tiexianwei population of $T$. tridentatus.

The results of this study highlight the importance of population genetic analyses for conservation efforts of $T$. tridentatus in Taiwan as well as Southeast Asia and Japan. Tachypleus tridentatus was historically abundant from Southeast Asia to its northern limit in Japan; however, serious depletion of this species has been reported, resulting from pollution, overharvesting for food and biomedical usage, and loss of suitable spawning and feeding grounds by coastal development (Itow, 1993; Chiu and Morton, 1999; Botton, 2001; Chen et al., 2004). Population genetic approaches can rapidly identify the population status (or population demography, such as population bottlenecks) and connectivity among local populations. The genetic structures of local populations provide information that can be used for implementing different conservation strategies. For example, the higher genetic diversity and larger census population size (Chen et al., 2004) found at Kinmen provide a reservoir of horseshoe crab genetic variation and supports the ongoing implementation of a marine protected area in Kinmen County (Chen et al., unpublished data). On the other hand, Tiexianwei with the bottleneck population deserves high priority in the establishment of a conservation and management plan for Penghu County. Translocation of horseshoe crabs from nearby populations, such as Dongwei, might be initiated to increase the genetic variability and to help prevent local extinction of the Tiexianwei population.

In summary, our preliminary study indicates that the Asian tri-spine horseshoe crab, Tachypleus tridentatus, exhibits population subdivision over a relatively small geographic range. The genetic data presented here indicate that the gene flow between Tiexianwei of Magong Bay and other populations is limited. It should be noted that the gene flow revealed by the mitochondrial AT-rich region represents the evolutionary history only of female tri-spine horseshoe crabs. Genetic information on male tri-spine horseshoe crabs contributing to the local population was not addressed by our study. Additional approaches using biparentally inherited markers from the nuclear genome (e.g., microsatellites) and extension of the geographic range of sampling are currently being undertaken and will be useful in elucidating the population structure and genetic connectivity of Tachypleus tridentatus throughout its distribution range from Southeast Asia to Japan.

\section{ACKNOWLEDGMENTS}

We give many thanks to Hsin-Yi Yeh, Po-Feng Lin, Sony Wu, and the staff of the Kinmen Fisheries Research Institute and the Penghu Marine Biology Research Center, facilities of the Taiwan Fisheries Research Institute, for sampling and field assistance. We thank members of the Evolution and Ecology Group, Research Centre for Biodiversity, Academia Sinica (RCBAS) for their comments before submission. This work was supported by an Academia Sinica Thematic Grant (2001-2004) to C. A. Chen, H.-L. Hsieh, and C.-P. Chen. This is contribution No. 36 of the Evolution and Ecology Group, RCBAS.

\section{REFERENCES}

Arnason E, Palsson S (1996) Mitochondrial cytochrome b DNA sequence variation of Atlantic cod, Gadus morhua, from Norway. Mol Ecol 5: 715-724

Avise JC (2001) Phylogeography. Academic Press, New York

Avise JC (2004) Molecular Markers, Natural History, and Evolution. Sinauer Associates, Sunderland, MA

Bernardi G, Talley D (2000) Genetic evidence for limited dispersal in the coastal California killifish, Fundulus parvipinnis. J Exp Mar Biol Ecol 255: 187-199

Botton ML (2001) The conservation of horseshoe crab: what can we learn from the Japanese experience? In "Limulus in the Limelight" Ed by JT Tanacredi, Kluwer Academic/Plenum, New York, pp 41-51

Brehm A, Harris DJ, Hernandez M, Cabrera V, Larruga J, Pinto F, Gonzalez AM (2001) Structure and evolution of the mitochondrial DNA complete control region in the Drosophila subobscura subgroup. Insect Mol Biol 10: 573-578

Chen C-P, Yeh H-Y, Lin P-F (2004) Conservation of horseshoe 
crabs in Kinmen, Taiwan: strategies and practices. Biodiv Conserv 13: 1889-1904

Chiu HMC, Morton B (1999) The Biology, Distribution, and Status of Horseshoe Crabs, Tachypleus tridentatus and Carcinoscorpius rotundicauda (Arthropoda: Chelicerata) in Hong Kong: Recommendations for Consevation and Management. The Swire Institute of Marine Science, University of Hong Kong, Hong Kong

Chiu HMC, Morton B (2004) The behaviour of juvenile horseshoe crabs, Tachypleus tridentatus (Xiphosura), on a nursery beach at Shui Hau Wan, Hong Kong. Hydrobiologia 523: 29-35

Collin R (2001) The effects of mode of development on phylogeography and population structure of North Atlantic Crepidula (Gastropoda: Calyptraeidae). Mol Ecol 10: 2249-2262

Frankham R, Ballou JD, Briscoe DA (2002) Introduction to Conservation Genetics. Cambridge University Press, Oxford

Gilbert DC (1994) SeqApp 1.9. A Biological Sequence Editor and Analysis Program for Macintosh Computers. Available at http:// ftp.indiana.edu

Hedgecock R (1986) Is gene flow from pelagic larval dispersal important in the adaptation and evolution of marine invertebrates? Bull Mar Sci 39: 550-565

Hoffman EA, Blouin MS (2004) Evolutionary history of the northern leopard frog: reconstruction of phylogeny, phylogeography, and historical changes in population demography from mitochondrial DNA. Evolution 58: 145-159

Itow T (1993) Crisis in the Seto Inland Sea: the decimation of the horseshoe crab. EMECS Newslett 3: 10-11

Johnson MS, Black R (1998) Increased genetic divergence and reduced genetic variation in populations of snail Bembicium vittatum in isolated tidal ponds. Heredity 80 : 163-172

Kimura M (1979) Model of effectively neutral mutations in which selective constraint is incorporated. Proc Natl Acad Sci USA 75: 1934-1937

King TL, Eackles MS (2004) Microsatellite DNA markers for the study of horseshoe crab (Limulus polyphemus) population structure. Mol Ecol Notes 4: 394-396

Lavrov DV, Boore JL, and Brown WM (2000) The complete mitochondrial DNA sequence of the horseshoe crab Limulus polyphemus. Mol Biol Evol 17: 813-824

Lessios HA, Kessing BD, Robertson DR (1998) Massive gene flow across the world's most potent marine biogeographic barrier. Proc Royal Soc London Ser B-Biol Sci 265: 583-588

Morton B (1999) On turtles, dolphins and, now, Asia's horseshoe crabs. Mar Poll Bull 38: 845-846

Nei M, Maruyama T, Chakraborty R (1975) The bottleneck effect and genetic variability in populations. Evolution 29: 1-10
Nei M (1987) Molecular Evolutionary Genetics. Columbia University Press, New York

Orti G, Pearse DE, Avise JC (1997) Phylogenetic assessment of length variation at a microsatellite locus. Proc Natl Acad Sci USA 94: 10745-10749

Palumbi SR (1994) Genetic divergence, reproductive isolation and speciation in the sea. Ann Rev Ecol Syst 25: 547-572

Parsons KE (1996) The genetic effects of larval dispersal depend on spatial scale and habitat characteristics. Mar Biol 126: 403-414

Pierce JC, Tan G, Gaffney PM (2000) Delaware Bay and Chesapeake Bay populations of the horseshoe crab Limulus polyphemus are genetically distinct. Estuaries 23: 690-698

Reynolds J, Weir BS, Cockerham CC (1983) Estimation of the coancestry coefficient: basis for a short-term genetic distance. Genetics 105: 767-779

Rogers AR, Harpending H (1992) Population growth makes waves in distribution of pairwise genetic differences. Mol Biol Evol 9: 552-569

Rutecki D, Carmichael RH, Valiela I (2004) Magnitude of harvest of Atlantic horseshoe crabs, Limulus polyphemus, in Pleasant Bay, Massachusetts. Estuaries 27: 179-187

Saunders NC, Kessler LG, Avise JC (1986) Genetic variation and geographic differentiation in mitochondrial DNA of the horseshoe crab, Limulus polyphemus. Genetics 112: 613-627

Schneider S, Roessli D, Excoffier L (2000) Arlequin Version 2.0: A Software for Population Genetics Data Analysis. Genetics and Biometry Laboratory, University of Geneva, Geneva, Switzerland

Sekiguchi K (1988) Biology of Horseshoe Crabs. Science House, Tokyo

Selander RK, Yang SY, Lewontin RC, Johnson WE (1970) Genetic variation in the horseshoe crab (Limulus polyphemus ), a phylogenetic "relic". Evolution 24: 402- 414

Shuster CN (1982) A pictorial review of the natural history and ecology of the horseshoe crab, Limulus polyphemus, with reference to other Limulidae. In "Physiology and Biology of Horseshoe Crabs: Studies on Normal and Environmentally Stressed Animals" Ed by J Bonaventura, C Bonaventura, S Tesh, Alan R. Liss, New York, pp 1-52

Slatkin M (1995) A measure of population subdivision based on microsatellite allele frequencies. Genetics 139: 457-462

Watts RJ, Johnson MS (2004) Estuaries, lagoons and enclosed embayments: habitats that enhance population subdivision of inshore fishes. Mar Freshwat Res 55: 641-651

(Received May 27, 2005 / Accepted October 12, 2006) 